Silva, W.P.M., Gunatilake, S. and Fasna, M.F.F., 2021. Optimising value during construction schedule acceleration. In: Sandanayake, Y.G., Gunatilake, S. and Waidyasekara, K.G.A.S. (eds). Proceedings of the $9^{\text {th }}$ World Construction Symposium, 9-10 July 2021, Sri Lanka. [Online]. pp. 433-444. DOI: https://doi.org/10.31705/WCS.2021.38. Available from: https://ciobwcs.com/papers/

\title{
OPTIMISING VALUE DURING CONSTRUCTION SCHEDULE ACCELERATION
}

\author{
W.P.M. Silva ${ }^{1}$, Sachie Gunatilake ${ }^{2}$ and M.F.F. Fasna ${ }^{3}$
}

\begin{abstract}
Construction Schedule Acceleration (CSA) can affect not just the time but many other project aspects. During a CSA, there can be many impacts having significant effects on the project value. Previous studies have highlighted the importance of considering quality, productivity and functionality at a CSA along with cost and time. The aim of this research is, therefore, to investigate how value can be optimised during a CSA process. A qualitative research approach was adopted. Altogether, ten semi-structured interviews were conducted. The interview data were transcribed and analysed using a manually performed content analysis.
\end{abstract}

This study has revealed types of CSA based on the purpose (delay minimising purpose or nondelay minimising purpose) and the party who initiates it. Cost, quality, functionality, productivity and profitability were identified as main value considerations during a CSA other than time. Applicability of value management (VM) job plan stages and Earned Value Management (EVM) indicators during different CSA stages to optimise value were also found. Finally, these findings were mapped in a framework to show how VM and EVM concepts could be used in enhancing value during a CSA. The framework conceptualises the relationship between "value" and CSA and how it varies upon distinct parties of a construction project during different stages and types of CSA. The proposed framework can be used as a guidance for optimising the value during the stages of a CSA.

Keywords: Construction schedule acceleration (CSA); Productivity; Scheduling; Value; Value management.

\section{INTRODUCTION}

A proper construction schedule is useful for stakeholders to plan the timing and sequence of project operations, calculate project completion date, predict and calculate the cash flow and evaluate the effect of changes (Mubarak, 2015). Even though, a typical project schedule is developed using existing methods based on the assumption of complete knowledge of project parameters, uncertainties in construction can affect the schedule during a project (Bruni et al., 2011). Those uncertainties can lead to project delays and can adversely affect the project success in terms of time, cost and quality (Theivendran and Gunathilake, 2015). In order to overcome delays and prevent contractors from making decisions based on a schedule consisted with inbuilt errors, certain alterations are necessary for the "As-Planned schedule" (Baldwin and Bordoli, 2014; Theivendran and Gunathilake, 2015). Construction schedule altering methods are considered as corrections to the "as built schedule" and can include alterations for key contract dates, logic links, constrains, activity durations and sequence of activities

\footnotetext{
1 Department of Building Economics, University of Moratuwa, Sri Lanka, pramodmalaka94@gmail.com

2 Department of Building Economics, University of Moratuwa, Sri Lanka, sachieg@uom.lk

3 Department of Building Economics, University of Moratuwa, Sri Lanka, fasna.fm2013@gmail.com
} 
(Baldwin and Bordoli, 2014). Eventhough there are few schedule alteration techniques, "construction schedule acceleration" stands as one of the most commonly used techniques.

CSA is mainly aimed at increasing the speed of a project and can occur due to instructions of owners' or contractors' own intiatives (Mubarak, 2015). CSA can affect not just the time but many other project aspects as well and hence, requires proper coordination among all project stakeholders. As highlighted by Thomas (2000), around 20-45 \% of labour efficiency losses have been observed due to disruption of normal utilization of resources which can occur during a CSA. Theivendran and Gunathilake (2015) also highlight additional costs, productivity problems, quality issues, conflicts, coordination problems and abortive works as possible problems faced due to CSA. Hence, it appears that there can be many impacts during a CSA that can have significant effects on the project value (Haddadia et al., 2016; Mubarak, 2015).

In a construction project, "value" is a much broader concept than just reducing the cost and its meaning could differ from one person to another depending upon their objectives (Karunasena and Gamage, 2011). In order to measure and enhance the value of a construction project, value techniques such as Earn Value Management (EVM) and Value Management (VM) are commonly used.

Past researchers have proposed different approaches for schedule acceleration. For instance, Moselhi and Esfahan (2013) have proposed a multi attributed decision-making environment to produce an executable plan for a schedule acceleration by considering cost and several other factors. Moreover, Thomas (2000) has proposed a tool for measuring the inefficiency of an accelerating process. In the Sri Lankan context, Theivendran and Gunathilake (2015) have revealed impacts of schedule acceleration and strategies to overcome those negative impacts. Similarly, previous studies have highlighted that cost should not be regarded as the only consideration during a CSA (see Mubarak, 2015) and noted the importance of considering other factors such as quality, productivity and functionality that affect the value during a CSA. This research, therefore, is aimed at investigating how value can be optimised during a CSA process. Herein, the paper first focuses on identifying and critically reviewing the concepts and types of CSA, impacts on project value during CSA and applicability of value techniques during CSA. It then goes on to discuss findings in relation to the value considerations along the CSA process and the suitability of applying value techniques to ensure optimum value during a CSA. Finally, based on the findings of this study a framework is proposed that can be used to ensure optimum value during a CSA.

\section{LITERATURE REVIEW}

\subsection{CONCEPTS AND TYPES OF CSA}

Construction delay, which is a recurring problem, has an adverse effect on time, cost and quality which are the three bases of golden triangle in construction projects (Mahamid, 2017; Theivendran and Gunathilake, 2015). Accordingly, CSA is often used to increase the speed in construction projects. Mubarak (2015) has defined project acceleration as shortening the normal duration of the project without reducing the original scope. Thomas (2000) described the acceleration as having more work to perform in the same period of time or having a shorter period of time to perform the same amount of work or combination of these two methods.

Acceleration can be categorised as "planned acceleration" (which is done before commencing the project) and "unplanned acceleration" (which takes place during the construction phase as a reactive approach once a delay has been identified or due to project scope change) (Noyce and Hanna, 1998). Methods of conducting a CSA under either of the aforementioned approaches can also be divided into two, namely "schedule crashing" and "fast tracking". Here, 
"schedule crashing" is the process of shortening the durations of certain tasks (Bowen, 2015). On the other hand, "fast tracking" is where certain tasks are carried out parallelly rather than doing them in sequence (Bowen, 2015). For example, this may involve starting the construction phase of a project while its design is still under development (Mubarak, 2010). Thus, it is clear from the above discussions that CSA can be mainly divided into two as "unplanned" and "planned" based on the when the decision to undertake CSA has been taken and each type can be carried out either by "schedule crashing" or "fast tracking". This can be summarised as shown in Figure 1.

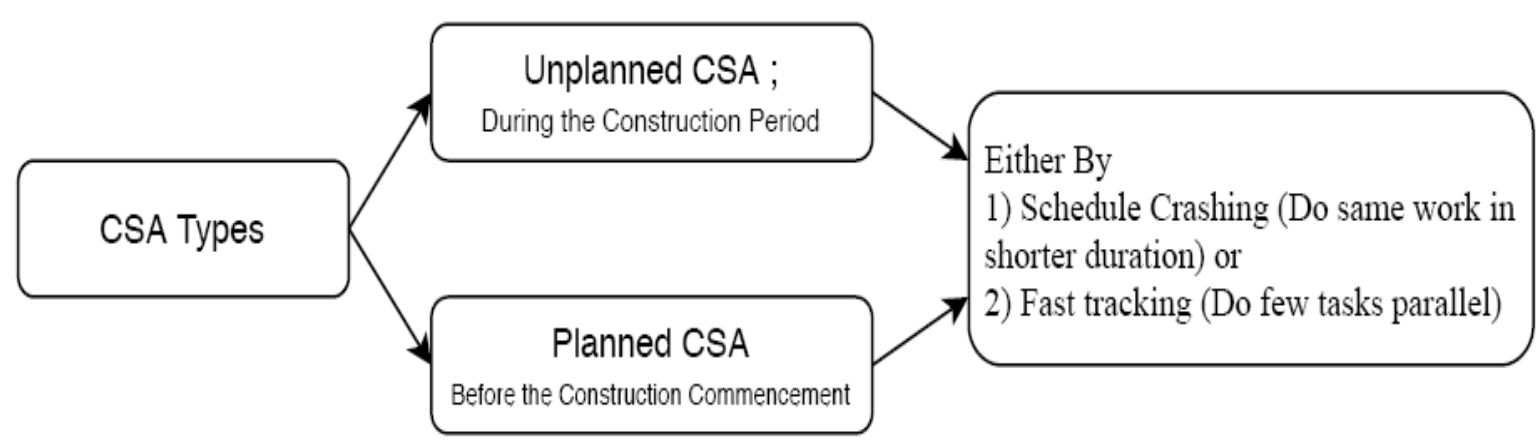

Figure 1: Types of CSA

\subsection{IMPACT ON VALUE DURING A CSA}

"Value" has been described as the ratio between functionality (quality) and cost. In other words, the optimum functionality and quality at the lowest possible cost leads to enhanced value (Ashworth and Hogg, 2000). The concept of value is highly subjective and can differ based on different perspectives of stakeholders as well as during different phases of a project (for e.g., refer Perez, et al., 2010). Even though CSA can clearly impact on construction project value, the behaviour of value expectations during a CSA, have still not been investigated in existing literature.

"Cost" can be considered as a main element of "value". Cost impacts of CSA will vary upon the method of CSA (i.e., schedule crashing and fast tracking) used. In fast tracking, where certain tasks are carried out in parallel without doing them subsequently, the level of effort remains same and hence, the direct costs may not change (Bowen, 2015; Kuehn, 2006). However, schedule crashing can increase the direct costs on most occasions as it involves in assigning additional technologies and resources to tasks to get them done earlier than scheduled (Kuehn, 2006; Mubarak, 2015). However, financing excessively for certain activities may reduce the productivity and efficiency due to site congestion and tiredness of workers and some activities which require decision making and creative skills should not be accelerated much (Kuehn, 2006; Mubarak, 2015). Hence, Mubarak (2015) has suggested that acceleration decisions should take into consideration factors other than cost to ensure value.

Construction industry is often criticised for its poor levels of performance compared to other industries. According to Tangen (2002), "performance" is an umbrella term, which is inclusive of profitability, productivity as well as quality. "Productivity", which can be defined as the ratio between input and output, also has a strong relationship towards value creation. Tangen (2002) has further stated that once productivity is connected with its financial connotations, it is termed as "profitability". During a CSA, disruptions to the normal utilization of resources are common. For example, Hanna et al. (2005) note that labour productivity can decrease as a result of more working hours. Similarly, Theivendran and Gunathilake (2015) have identified productivity and quality issues as negative impacts during CSA. From all these findings it can 
be concluded that CSA process has an impact on overall performance of the project and therefore the factors related to performance, namely "productivity", "profitability" and "quality", will be impacted.

"Functionality" is considered as a main success criterion of any construction project and also it has been mentioned that, once the functionality of a project becomes low, the project life cycle will also come to an end (Nguyen et al., 2004; Kelly, et al., 2015). Accordingly, sustaining the functionality of the project even during a value adding activity is of critical importance as well (Norton and McElligott as cited in Ashworth and Hogg, 2000).

Hence, from the literature review, cost, quality, functionality, productivity and profitability could be identified as main value considerations other than time during a CSA.

\subsubsection{Applicability of Value Techniques during a CSA}

There are numerous value techniques available and among them Value Management and Earned Value Management are the significant techniques related to construction industry (Ashworth and Hogg, 2000; Karunasena and Gamage, 2011; Kliniotou, 2004). The following sections discuss these two techniques, which have been considered in this study.

Value Management (VM) has been defined by Male (2002) as a proactive approach which solves problems and discloses the client value system by analysing time, cost and quality. VM has also been highlighted as a more beneficial tool for clients as it fulfils clients' needs and demands, which are of paramount importance in a construction project (Perera, et al., 2011). Kelly and Male (1993) has indicated that VM can be adopted from initial stages to completion. VM has been recognised as a proactive approach which solves problems and disclose the client value system by analysing time, cost and quality which are all factors highly impacted during a CSA (Male, 2002; Mubarak, 2015;). Ashworth and Hogg (2000) has mentioned five stages in a VM process as follows;

- Information gathering - Collect required information, functional and process analysis may assist.

- Brainstorming session - Innovative and creative ideas on the subject are considered.

- Idea evaluation - Selection of the best choice/option as raised in previous steps, the selection should be based on the subject and the situation.

- Development - Study further on the selected choice / option to determine whether to confirm or not.

- Implementation - Plan for implementation is presented to client representatives

However, a gap remains on exploring possibilities of aforementioned VM stages to optimise value during CSA.

Earned Value Management (EVM) can be considered as a tool for project performance which compares the actual work with planned work in monetary terms only (Anondho, 2017; Dissanayake, 2010). Raby (2000) has highligted the uses of EVM as facilitating a uniform unit of measure for project progress and providing a sound basis for the analysis of cost performance. In terms of project management, EVM can be considered as an efficient and wellknown tool which assists in making managerial decisions at a construction site (Czemplik, 2014). Specific parameters and indicators that are used to reflect costs and progress from actual and planned perspectives in EVM are summerised in Table 1 (Baldwin and Bordoli, 2014; Czarnigowska, 2008; Tzaveas, 2010); 
Table 1: Indicators and parameters of EVM

\begin{tabular}{|c|c|c|}
\hline Indicator / Parameter & $\begin{array}{l}\text { Formula } \\
\text { (Source: Baldwin and } \\
\text { Bordoli, 2014) }\end{array}$ & $\begin{array}{c}\text { Description } \\
\text { (Sources: Czarnigowska, 2008; Tzaveas, 2010) }\end{array}$ \\
\hline Schedule Variance (SV) & $=\mathrm{BCWP}-\mathrm{BCWS}$ & $\begin{array}{l}\text { Difference between the actual progress and } \\
\text { the planned progress }\end{array}$ \\
\hline $\begin{array}{l}\text { Schedule Performance } \\
\text { Index (SPI) }\end{array}$ & $=\mathrm{BCWP} / \mathrm{BCWS}$ & $\begin{array}{l}\text { Ratio between the actual progress and the } \\
\text { planned progress, if below } 1 \text {, then considered } \\
\text { as a delay. }\end{array}$ \\
\hline Cost Variance (CV) & $=\mathrm{ACWP}-\mathrm{BCWP}$ & $\begin{array}{l}\text { Deviation between planned and actual cost of } \\
\text { works done }\end{array}$ \\
\hline $\begin{array}{l}\text { Cost Performance Index } \\
\text { (CPI) }\end{array}$ & $=\mathrm{BCWP} / \mathrm{ACWP}$ & $\begin{array}{l}\text { Ratio between planned and actual cost of } \\
\text { works done, if below } 1 \text {, then considered as a } \\
\text { cost over-run }\end{array}$ \\
\hline $\begin{array}{l}\text { Estimate At Completion } \\
\text { (EAC) }\end{array}$ & $\begin{array}{l}=\mathrm{ACWP}+\{(\mathrm{BAC}- \\
\mathrm{BCWP}) / \mathrm{PF}\}\end{array}$ & $\begin{array}{l}\text { Based on the current progress, estimates the } \\
\text { cost at completion }\end{array}$ \\
\hline $\begin{array}{l}\text { To Complete } \\
\text { Performance Index } \\
\text { (TCPI) }\end{array}$ & $\frac{\text { BAC-BCWP }}{\text { BAC-ACWP }}$ & $\begin{array}{l}\text { Ratio between the value of work left and the } \\
\text { balance money left from the budget. }\end{array}$ \\
\hline $\begin{array}{l}\text { Legend: } \\
\text { BCWP = Budgeted Cost } \\
\text { BCWS = Budgeted Cost } \\
\text { ACWP = Actual Cost of } \\
\text { BAC = Budget At Comp } \\
\text { PF = Project Factor (Fact }\end{array}$ & $\begin{array}{l}\text { f Work Performed (Ear } \\
\text { f Work Scheduled } \\
\text { Vork Performed } \\
\text { etion } \\
\text { or differs from project's }\end{array}$ & Value) \\
\hline
\end{tabular}

Even though there are value techniques such as VM and EVM used in the construction industry the applicability of those techniques particularly during a CSA has not been investigated in the existing literature. Thus, the next stages of this study attempt to address this gap.

\section{RESEARCH METHOD}

Respondents' opinions on value concepts and their knowledge about any possibilities of using value techniques such as VM and EVM at a CSA environment are subjective. Considering the highly subjective nature of the opinions on the phenomenon being investigated a qualitative approach was adopted for this research. Considering that CSA is a highly practical phenomenon, expert interviews were carried out to collect in-depth insights from construction professionals on the value considerations and applicability of VM and EVM during a CSA. Semi-structured interviews were used with open ended questions allowing respondents to elaborate more when answering. Construction project professionals such as project managers, planning engineers and quantity surveyors from both client and contractor parties, who have been actively involved in CSA related activities were selected as respondents for the expert interviews. Employing convenience sampling technique, altogether ten experts having more than 5 years of construction industry experience were selected. Experts from the Contractor's side have been coded from "EC1" to "EC5" while the rest of the respondents of Client's side were given a code from "EE1" to "EE5". Details of selected respondents are given in Table 2. 
Table 2: Details of expert interview respondents

\begin{tabular}{cclc}
\hline $\begin{array}{c}\text { Respondent } \\
\text { Code }\end{array}$ & $\begin{array}{c}\text { Contractor/ } \\
\text { Employer }\end{array}$ & \multicolumn{1}{c}{ Professional background } & Experience \\
\hline EC1 & & Project manager & 22 years \\
EC2 & & Civil Engineer / Project Manager & 14 years \\
EC3 & Contractor & Project Manager & 10 years \\
EC4 & & Quantity Surveyor & 10 years \\
EC5 & & Project Manager & 8 years \\
\hline EE1 & & Quantity Surveyor / Director & 25 years \\
EE2 & Consultant & Civil Engineer / Director & 20 years \\
EE3 & (Employer's & Quantity Surveyor / Project manager & 8 years \\
EE4 & representative) & Resident Engineer & 8 years \\
EE5 & & Civil Engineer & 7 years \\
\hline
\end{tabular}

The collected qualitative data from the expert interviews were analysed methodically using manual content analysis.

\section{FINDINGS AND DISCUSSION}

This section presents the findings from the expert interviews in terms of CSA types, value considerations along the CSA process and the applicability of VM and EVM during a CSA process.

\subsection{TYPES OF CSA}

According to Figure 1, CSA can be categorised as "planned CSA" and "un-planned CSA". The expert interview findings revealed that "un-planned CSA" could be further sub-divided based on the reason for acceleration as a delay minimising technique or a non-delay minimising technique.

As a delay minimising technique: Either contractor (To prevent from liquidated damages) or client (Client representative may order the contractor to accelerate) may initiate CSA when they realize that the project is going at a delay. The party who is responsible for the delay will bear the cost.

As a non-delay minimising technique: Mainly, initiated by clients. The client requires accelerating the project to complete the project earlier than previously expected to gain business benefits. However, the contractor may also initiate this type of technique to accelerate a project when sharing resources among several projects. The party who initiates the acceleration will typically bear the cost. Not commonly found.

The above findings on types of CSA were highlighted by most of the expert interviewees and those types can be summarised as shown in Figure 2.

Majority of the respondents agreed that "unplanned CSA" is more common as a delay minimising technique with planned acceleration not being practiced much in the local context. Among the types of un-planned acceleration, types A and B were found to be more common. 


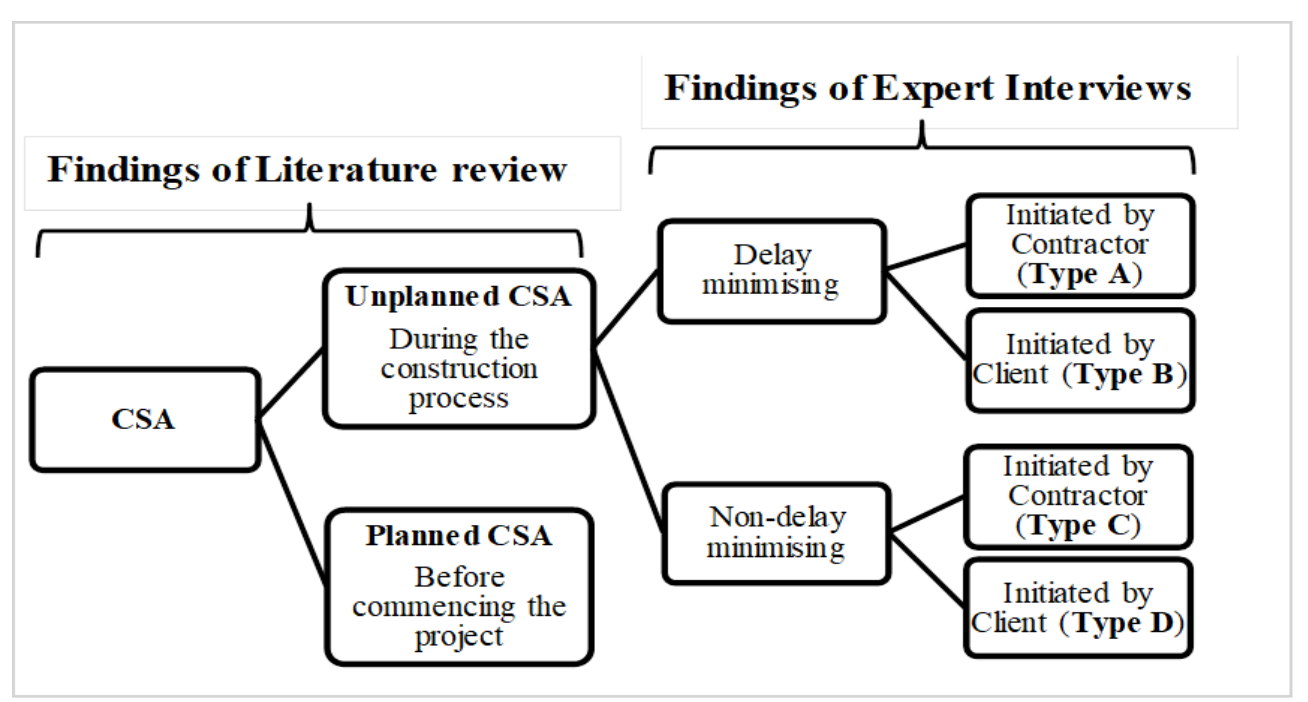

Figure 2: Types of CSA

Most of the expert interviewees stated that it is not possible to carry out a CSA process in a methodical manner due to practical constraints such as client's sudden instructions to accelerate certain activities or the entire project and lack of commitment of the professionals to plan the acceleration properly. However, the findings revealed that the CSA process could be broadly categorized into three phases as decision-making stage, detailed planning stage and physical CSA stage. Hence the following sections go on to present the findings in relation to value considerations and the applicability of VM and EVM during each of these three stages separately.

\subsection{DECISION MAKING STAGE}

This stage mainly involves the deciding whether to accelerate the project or not. At this stage, respondents from both client and contractor have mentioned that they are not giving much concern to cost during a delay minimizing CSA. For instance, EC1 commented “... if the acceleration is initiated by the Contractor itself in order to recover a delay, cost will not be considered much..." During a delay minimising CSA, profitability and productivity were found to be key value considerations for contractors during this stage. Cost appears to be a major value consideration only during non-delay minimising CSAs, which are initiated by contractors. On the hand, respondents from client's side highlighted functionality and quality as main value considerations when deciding whether or not to accelerate a project.

When exploring the applicability of the main VM steps during the decision-making stage of CSA process, it appears that out of the identified main steps in a VM job plan, mainly information gathering and evaluation were applicable. Based upon the expert interviews, main information required for a decision to accelerate was "comparison between as-planned and actual progress". However, respondents such as EE1 and EE2 were firmly convinced that contractors do not follow the as-planned construction schedule. Similarly, EC1 also noted "...only the date of completion is taken into account. But if the consultants and employers are strict, as-planned schedule will be taken into consideration to a certain extent...". Besides this, procuring limitations, resource requirements and availability, cash flows, and contractual provisions were also important information needed prior to taking a decision to accelerate. EC1 particularly highlighted the importance of being aware of procurement and resource limitations by adding, "...in order to accelerate, some materials needed to be imported and it will take months of time. So, in that type of a situation, acceleration decision will not be worthwhile...”. 
Applicability of the identified EVM indicators; namely SV, CV, TCIP, BAC and EAC, in assisting making the decision to accelerate was also inquired. Interview findings revealed that EVM was not a useful value technique for planned CSA as typically the decision to accelerate had to be taken before actual construction and hence, there is no comparison of actual construction progress with the planned schedule. However, EC5 noted that a derived form of BAC and EAC were sometimes used to get an idea about the cost and the time of completion to assist in decision-making. For un-planned CSA, EVM indicators such as SV, CV and EAC were useful to compare as-planned and actual progress.

\subsection{Detailed Planning Stage}

After taking the CSA decision, next stage is to prepare a detailed plan for the CSA. Respondents noted that considerations such as (1) which activities are to be accelerated, (2) up to which extent they should be accelerated, and (3) the method of acceleration of each activity were often determined at this stage.

For both contractors and clients, "productivity" appears to be a main value consideration during this stage. In addition, from the client's point of view, "functionality" and "quality" are also main value considerations during this stage. However, when a planned CSA (which takes place before commencing the project) is considered, "cost" and "profitability" also become important as considering these factors in early stages can positively impact the ultimate goals. Besides these, respondents also highlighted that doing activities in an accelerated manner can lead to safety issues and added that particular attention should also be given to safety during the detailed planning and physical CSA stages.

"Information gathering" (i.e., the first stage of VM job plan) was again found to be relevant during this detailed planning stage as well. In addition to the information identified as important in decision making stage (such as comparison between planned and actual progress, cash flows, procuring schedules, contractual provisions and resource requirements), other information identified as essential to this particular stage included BOQ, specifications, quality standards and "look ahead schedules of previous months". EC3 also added that labour histograms can be a significant element under resource requirement schedules.

According to the expert interviewees, brainstorming for creative solutions was another useful VM stage, applicable during this CSA stage. Respondents mentioned that creative ideas such as substituting of prefabricated materials instead of conventional materials and initiating creative project management strategies were obtained from brainstorming during CSA activities. However, respondents also highlighted the importance of ensuring the initial scope and functionality of the project when taking such creative ideas on board.

If there are more than one method to accelerate a particular task, such options must be evaluated in terms of cost and time. Basis of evaluating options depend on the purpose of CSA. As stated by $\mathrm{EC} 1$, "...If the main purpose is earning profit, the option with the highest profit will be preferred and if the purpose is just to shorten the duration of the project most practical option will be selected. That's the option with less risk to complete... According to EE4, cost benefit analysis, which is also a value technique, could assist in such evaluations as it allows all the negative and positive impacts in addition to acceleration costs to be taken into consideration. Respondents also noted the importance of contractors making collaborative decisions together with consultants and client, especially if there is a change to the design or major preliminary work in order to conduct the acceleration. According to EE3, a summary including all the considered options can be presented to the client at this stage in a simple, understandable manner for approval. 
With regard to the identified EVM indicators, respondents agreed that SV and EAC can be used to ascertain "up to which extent those selected activities should be accelerated". EC5, who was a respondent from a contractor organization, highlighted that in instances where acceleration is done to address a delay taken place due to contractor's own fault, they only considered the aforementioned EVM indicators and did not consider any cost related EVM indicators. However, the respondents agreed that other EVM indicators were also used at least to a certain extent when cost and time were both critical during a CSA. In general, it can be concluded that all the identified EVM indicators are applicable in obtaining the optimum value during the detailed planning stage of CSA.

\subsection{PHySiCAL CSA STAGE}

This stage involves the actual physical implementation of the CSA. From the contractor's perspective, "productivity", "cost" and "profitability" were highlighted as main value considerations. EC1 and EE2 both highlighted that the expected progress or the productivity can be affected during a CSA by labour inefficiencies and material shortages. "Functionality" and "quality" were identified as main value considerations from the client's point of view. As highlighted by EC2, quality issues can arise during a CSA due to inabilities to recruit skilled laborers and to supply quality material to fulfil excessive demand within the time constraints. Additionally, interviewees also emphasised the importance of safety and environmental considerations which can enhance corporate reputation during physical CSA stage.

\subsection{FRAMEWORK TO OBTAIN OPTIMUM VALUE DURING CSA}

Figure 3 presents the framework developed to ensure optimum value during a CSA. CSA process has been presented divided into the three main stages identified; namely decision making, detailed planning and physical CSA. In each stage, applicable VM and EVM techniques to achieve optimum value are presented. Since the priority given by the parties for value considerations differ along the three stages as mentioned in sections 4.2, 4.3 and 4.5, those value considerations are included for each stage in their priority order. The process flows and information flows are separately indicated in the framework to improve clarity. The proposed framework is more suitable for unplanned accelerations which are decided after the project commencement date with the aim of minimizing a delay (i.e., Types A and B). The framework will be particularly useful for contractors to obtain optimum value during a CSA. "Value" from the Contractor's perspective can be optimized by giving more concern to the prioritized value considerations in each stage of CSA and by following the steps of VM process and using some EVM indicators as illustrated in the framework.

\section{DISCUSSION AND CONCLUSIONS}

CSA is about completing a project or a particular activity of a project before the scheduled date or the date in which that task would have been completed at its normal pace. Two main CSA types were identified as "planned CSA" and "unplanned CSA". Unplanned CSA has been further divided into four based on the purpose (i.e., delay minimizing or non-delay minimizing) and the party who initiates it. However, unplanned delay minimizing CSA types (Types A and B) appear to be more common in the local context.

The literature review identified cost, quality, functionality, productivity and profitability as main value considerations other than time affected during a CSA. Perez et al. (2010) stated that "value" is not only generated by the client and can vary from the stakeholders" point of view. 


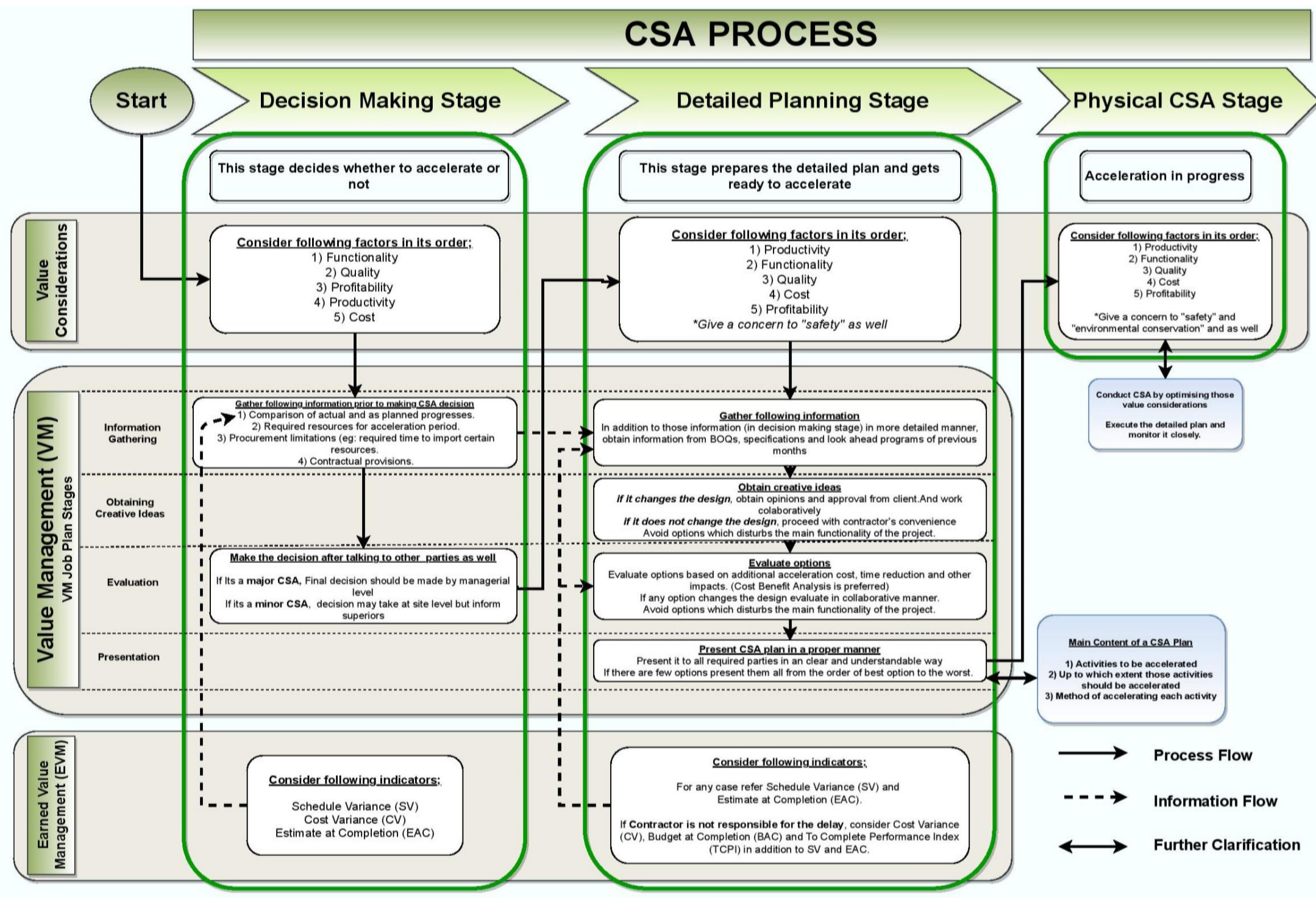

Figure 3: Framework to obtain optimum value during CSA 
This was also supported by expert interview findings where it was found that value expectations differ between client and contractor during a CSA. Additionally, it was found that the value considerations can vary based on the type and stage of CSA as well. For instance, while "cost" was a main value consideration for the entire CSA process, "quality" and "functionality" have become major concerns during decision making stage.

The applicability of VM and EVM during the two initial stages of CSA were highlighted. Particularly to the decision-making stage, information gathering and evaluation steps of a VM job plan was applicable and SV, CV and EAC were the applicable EVM indicators to that stage. Detailed planning stage can be assisted by information gathering, brainstorming, evaluation and presentation stages of VM job plan while obtaining certain information from EVM indicators namely SV, EAC, CV, TCPI and BAC. Further, two characteristics of a VM job plan namely "working in a collaborative manner" and "not disturbing to the main functionality of the project" have proven to be required at decision making stage and detailed plan preparation stage of a CSA. The findings were used to develop a framework to ensure optimum value during a CSA.

In order to obtain the optimum value during a CSA and to smoothen the CSA process, certain recommendations would be useful for the industry such as monitoring the construction progress properly, communicating effectively, maintaining the main functionalities of the project (during a CSA) and replacing conventional methods of construction with modern technological methods. This study has paved paths to further studies namely to investigate the applicability of Cost Benefit Analysis (CBA) for a planned CSA and to study the strategies to enhance productivity during the physical CSA stage.

\section{REFERENCES}

Anondho, B., Rarasati, A.D., Latief, Y. and Mochtar, K., 2017. Probabilistic Construction Project Duration Prediction Models for High Rise Building Based on Earned Schedule Method in Jakarta. International Journal of Innovation, Management and Technology, 8(6), pp. 477-481.

Ashworth, A. and Hogg, K., 2000. Added value in design and construction. Essex, England: Pearson Education Limited.

Baldwin, A. and Bordoli, D., 2014. A handbook for construction planning and scheduling. Chichester, West Sussex, UK: John Willey \& Sons Ltd.

Bowen, B., 2015. Schedule Compression Briefing. Ottawa.

Bruni, M. E., Beraldi , P. and Gue, F., 2011. A scheduling methodology for dealing with uncertainty in construction projects. International Journal for Computer-Aided Engineering and Software, 28(8), pp. 1064-1078.

Czarnigowska, A., 2008. Earned value method as a tool for project control. Budownictwo i Architektura, pp. 15-32.

Czemplik, A., 2014. Application of earned value method to progress control of construction projects. Procedia Engineering, 91, pp. 424-428.

Dissanayake, P. G., 2010. Earned value management system as a project management tool for major multidisciplinary projects. Kandy, pp. 14-21.

Duy Nguyen, L., Ogunlana,, S. O. and Thi Xuan Lan, D., 2004. A study on project success factors in large construction projects in Vietnam. Engineering, Construction and Architectural Management, 11(6), pp. 404-413.

Haddadi, A., Johansen, A. and Andersen, B., 2016. A conceptual framework to enhance value creation in construction projects. Procedia Computer Science, 100, pp. 565-573.

Karunasena, G. and Gamage, O., 2011. Value Achievement in Construction industry. Colombo, pp. 152161. 
Kelly, J. and Male, S., 1993. Value management in design and construction. E\&FN SPON.

Kliniotou, M., 2004. Identifying, measuring and monitoring value during project development. European Journal of Engineering Education, 29(3), pp. 367-376.

Kuehn, U., 2006. Integrated cost and schedule control in project management. Vienna: Congress cataloging.

Mahamid, I., 2017. Analysis of schedule deviations in road construction projects and the effects of project physical characteristics. Journal of Financial Management of Property and Construction, 22(2), pp. 192-210.

Male, S., 2002. Building the business value case. In: J. Kelly, R. Morledge and S. Wilkinson, eds. Best value in construction. Blackwell Publishing Company.

Moselhi, O. and Esfahan , N. R., 2013. Project schedule compression: A multi-objective methodology. Construction Innovation, pp. 374-393.

Mubarak, S., 2015. Construction project scheduling and control. $3^{\text {rd }}$ ed. Hoboken, New Jersey: John Wiley $\&$ Sons.

Noyce, D.A. and Hanna, A.S., 1998. Planned and unplanned schedule compression: The impact on labour. Construction Management \& Economics, 16(1), pp. 79-90.

Perera, S., Hayles , C. and Kerlin, S., 2011. An analysis of value management in practice: the case of Northern Ireland's construction industry. Journal of Financial Management of Property and Construction, 16(2), pp. 94-110.

Pérez, P.B., González-Cruz, M.C. and Pastor-Ferrando, J.P., 2010. Analysis of construction projects by means of value curves. International Journal of Project Management, 28(7), pp.719-731.

Raby, M., 2000. Project management via earned value. Journal of Facilities Management, pp. 69-80.

Tangen, S., 2002. Understanding the concept of productivity. $7^{\text {th }}$ Asia-Pacific Industrial Engineering and Management Systems Conference, Taipei, pp. 18-22.

Theivendran, J. and Gunathilake, S., 2015. A study on schedule compression techniques on construction projects in Sri Lanka. Colombo, pp. 66-76.

Thomas, H.R., 2000. Schedule acceleration, workflow, and labor productivity. Journal of Construction Engineering and Management, 126(4), pp.261-267.

Tzaveas, T. K. S. and. K. G., 2010. Analysis of project performance of a real case study and assessment of earned value and earned schedule techniques for the prediction of project completion date.. s.1., s.n., pp. 752-780.

Tzaveas, T., Katsavounis, S. and Kalfakakou, G., 2010. Analysis of project performance of a real case study and assessment of earned value and earned schedule techniques for the prediction of project completion date. In Proceedings of IPMA Conference, pp. 752-759. 